\title{
T-LYMPHOBLASTIC LEUKEMIA/LYMPHOMA IN MACEDONIAN PATIENTS WITH NIJMEGEN BREAKAGE SYNDROME
}

Kocheva SA ${ }^{1}$, Martinova $\mathrm{K}^{1}$, Antevska-Trajkova $\mathrm{Z}^{1}$, Coneska-Jovanova B ${ }^{1}$, Eftimov A², Dimovski $\mathrm{AJ}^{2}$

*Corresponding Author: Svetlana A. Kocheva, M.D., Ph.D., Department of Hematology and Oncology, University Children's Hospital, Mother Teresa 17, 1000 Skopje, Macedonia. Tel:+38-971-378-184. E-mail: svetlana.kocheva@t.mk

\begin{abstract}
Nijmegen breakage syndrome (NBS) is a rare autosomal recessive chromosomal instability disorder characterized by microcephaly, immunodeficiency, radiosensitivity and a very high predisposition to malignancy. The gene responsible for the disease, $N B S 1$, is located on chromosome 8q21 and encodes a protein called nibrin. After identification of the gene, a truncating 5 bp deletion, 657-661delACAAA, was identified as the disease-causing mutation in patients with the NBS. In this report, we describe two patients with NBS and T-lymphoblastic leukemia/ lymphoma in a Macedonian family. To the best of our knowledge, this is the first family with NBS reported from Macedonia. Both children presented with microcephaly, syndactyly and the development of T cell lymphoblastic lekemia/lymphoma at the age of 7 and 10 years, respectively. The molecular analysis of NBSI genes in our patients showed homozygosity for the 657 del 5 mutation in the NBS1 gene. The parents were heterozygotes for the $657 \mathrm{del} 5$ mutation and they had no knowledge of a consanguineous relationship. The first child was treated with the International BerlinFrankfurt-Münster (BFM)-Non Hodgkin lymphoma (NHL) protocol and achieved a complete remission
\end{abstract}

\footnotetext{
${ }^{1}$ University Children's Hospital, Medical Faculty, University "St. Cyril and Methodius," Skopje, Republic of Macedonia

${ }^{2}$ Center for Biomolecular Pharmaceutical Analyses, Faculty of Pharmacy, University "St. Cyril and Methodius," Skopje, Republic of Macedonia
}

that lasted for 21 months. Subsequently, he developed a medullar relapse with hyperleukocytosis and died due to lethal central nervous system (CNS) complications. The second child was treated according to the International Collaborative Treatment Protocol for Children and Adolescents with Acute Lymphoblastic Leukemia 2009 (AIOP-BFM ALL 2009) protocol. Unfortunately, remission was not achieved.

Keywords: Molecular analysis; Nijmegen breakage syndrome (NBS); T-cell leukemia/lymphoma.

\section{INTRODUCTION}

Nijmegen breakage syndrome (NBS) is a relatively rare chromosomal instability disorder with an estimated incidence of less than 1:100,000 live births $[1,2]$. The disease seems to be more prevalent among Central and Eastern European populations, with Polish patients constituting approximately half of all registered NBS patients worldwide. Nijmegen breakage syndrome is clinically characterized by microcephaly, typical facial appearance, growth and mental retardation, immunodeficiency and a high predisposition to lymphoid malignancies, in particular to lymphoma and leukemia $[1,2]$. Important additional features are skin abnormalities, particularly café au lait spots and vitiligo, as well as clinodactyly and syndactyly. The laboratory analyses demonstrate immunodeficiency characterized by the involvement of both humoral and cellular immunity. The NBS patients' cells display chromosome instability and hypersensitivity to the 
lethal effects of agents, such as ionizing radiation, that induce double-strand breaks in genomic DNA. The disease is caused by mutations in the NBSI gene that is located on chromosome 8q21 [3-5]. The NBS1 gene encodes nibrin, a member of the Mre11/ Rad50/nibrin complex involved in the cellular response to DNA double-strand breaks [6-8]. After identification of the gene, a truncating 5 bp deletion, 657-661delACAAA, was identified as the diseasecausing mutation in patients with the NBS [9-11]. Patients with the same genotype may vary in their phenotypic expression. In this report, we describe the clinical features and molecular characterization of two patients with NBS in a Macedonian family. To the best of our knowledge, this is the first family with NBS reported from Macedonia.

\section{CLINICAL REPORT}

Case 1. The first patient (proband 1) was a 7-year-old boy of Macedonian origin. He was referred to the Hematology Department, University Pediatric Clinic, Skopje, Republic of Macedonia, with lymphadenopathy in the neck region. He was the first-born child after a normal pregnancy of 38 weeks duration, with a birth weight of $2500 \mathrm{~g}$ (data concerning length and head circumference at birth were not available). The neonatal period passed without complications. The development of language skills was normal. There was no history of developmental regression. His admission to the hospital occurred after a few-days history of cough, fever and enlarged lymph nodes. The physical examination revealed bilateral lymphadenopathy, hepatomegaly, microcephaly, and syndactyly of the toes. A lymph node fine needle biopsy confirmed the diagnosis of malignant T-cell acute lymphoblastic lymphoma [Non Hodgkin lymphoma (T-NHL)]. The patient was treated according to the International Berlin-Frankfurt-Münster (BFM 1990) protocol consisting of induction, consolidation, reinduction and maintenance. During treatment, no significant side effects of chemotherapy were observed. $\mathrm{He}$ achieved a complete remission that lasted for 21 months. Subsequently, he developed a medullar relapse with hyper-leukocytosis and died due to lethal central nervous system (CNS) complications.

Case 2. The second patient (proband 2) was a 9.5-year-old boy, the second-born child in the same family. He was also born after a normal pregnancy. His psychomotor development was normal, but the physical examination showed microcephaly, micrognatia and syndactyly of the toes. He was admitted to the Hematology Department at the age of 9.5 with fever, disseminated lymphadenopaty, hepatosplenomegaly and leucocytosis of $27,000 \times$ $10^{9} / \mathrm{L}$. The evaluation of the peripheral blood smear showed the presence of $32.0 \%$ blast cells. The diagnosis of T-cell acute lymphoblastic leukemia (T-ALL) was established based on a standard immunohystological panel analysis. It was quite clear that the malignant disease in both children in this family was partly due to the clinical presentation of NBS. The patient was treated with the International Collaborative Treatment Protocol for Children and Adolescents with Acute Lymphoblastic Leukemia 2009 (AIOP-BFM ALL 2009) protocol. A remission was not achieved in this patient and he passed away after a very brief and severe episode of gramnegative sepsis and systemic inflammatory response syndrome (SIRS) during bone marrow aplasia after an intensive chemotherapy block in the induction phase for bone marrow transplantation.

Family History. The probands 1 and 2 were children born to non consanguineous parents. The mother was of Croatian ancestry, while the father was of Macedonian origin. The family history was negative for hereditary or malignant disorders.

Molecular Diagnosis and Genetic Counseling. Genetic analysis to determine the mutation in the NBS1 gene was made after the manifestation of acute leukemia in the second patient. Mutation detection using genomic DNA was performed by polymerase chain reaction (PCR) with specific primers for the human NBS1 gene, followed by an automated DNA sequence analysis. The molecular analysis of the family members showed homozygosity for the 657 del5 mutation in the NBS1 gene in both patients. The parents were heterozygotes for the $657 \mathrm{del} 5 \mathrm{mu}-$ tation. They had no knowledge of a consanguineous relationship. Families with a $25.0 \%$ risk of having an affected child may be offered prenatal diagnosis if both disease-causing mutations in the $N B N$ gene are established. The molecular analysis is the method of choice. Fetal DNA for analysis can be obtained either by chorionic villus sampling (CVS) or by amniocentesis. Siblings of a patient's parents are at $50.0 \%$ risk of being carriers. Heterozygous carriers 
of an NBN mutation do not present with any symptoms. However, in some population studies, a strong association with an increased cancer risk was noted for carriers of the founder mutation [12].

\section{DISCUSSION}

Nijmegen breakage syndrome has been reported in different populations, but so far, most of the patients have been of Slavic origin and carry a typical mutation $(657$ de15) on the NBS1 gene $[1,2]$. To the best of our knowledge, this is the first family with NBS reported from Macedonia. B-cell lymphomas are the most frequently encountered malignancies in NBS, but cases of precursor T-cell, B-cell leukemia or myeloid leukemia, have also been reported $[13,14]$. Data from the Nijmegen registry indicate that patients with NBS develop cancer before the age of 21 years [1]. The majority of lymphomas in NBS were diagnosed in patients younger than 15 years of age with lymphomas as the leading cause of death $[1,2]$. Due to the small number of patients with NBS and NHL, experience related to their treatment is limited $[13,14]$. The treatment outcome is poor, and drug dose reductions are warranted to reduce serious toxic effects in these patients.

Our patients developed T-NHL and T-ALL at the age of 7 and 9.5 years, respectively. The first patient received more than $80.0 \%$ of the recommended doses of chemotherapy. During treatment, no major toxic or infectious complications were observed. He achieved a complete remission that lasted for 21 months. The remission was not achieved in his brother and he died after a very brief and severe episode of a gram-negative sepsis and SIRS. Immunodeficiency in NBS is significant, affecting both the humoral and cellular immunity but it is highly variable, with a tendency to progress over time [14]. In our patients, we found a normal humoral immune system (cellular immunity was not tested). The diagnosis of NBS was established based on the clinical characteristics and molecular analyses of the NBSI gene. The constitutional karyotypes of the NBS patients were normal. Cultured $\mathrm{T}$ cells often show a poor proliferative capacity, making the cytogenetic analysis far from easy. Early diagnosis of NBS is very important in order to avoid severe recurrent infections by employing appropriate prophylaxis in order to avoid unnecessary exposure to radiation for diagnostic purposes and the adverse reactions of the radiotherapy for the treatment of malignant tumors. It is important in cases presenting with malignancy and suggestive clinical features, that the diagnosis is confirmed prior to the initiation of treatment. Diagnosis on a genetic level provides prevention of the disease in families who are at an increased risk for having a sick child with NBS. Establishing an early genetic diagnosis will provide prenatal diagnosis in each successive pregnancy and prevent the recurrence of the disease in the family.

\section{ACKNOWLEDGMENTS}

We are grateful to the family for their consent for the publication of these results.

Declaration of Interest. The authors report no conflicts of interest. The authors alone are responsible for the content and writing of this article.

\section{REFERENCES}

1. International Nijmegen breakage syndrome study group. Nijmegen breakage syndrome. Arch Dis Child. 2000; 82(5): 400-406.

2. Wegner RD, Chrzanowska K, Sperling K, Stumm M. Ataxia-telangiectasia variants (Nijmegen breakage syndrome) In: Ochs HD, Smith CIE, Puck JM, Eds. Immunodeficiency Disorders: A Molecular and Genetic Ap-proach. Oxford, UK: Oxford University Press. 1999: 324-334.

3. Carney JP, Maser RS, Olivares H, Davis EM, Le Beau M, Yates JR III, et al. The hMre11/ hRad50 protein complex and Nijmegen breakage syndrome: Linkage of double-strand break repair to the cellular DNA damage response. Cell. 1998; 93(3): 477-486.

4. Matsuura S, Tauchi H, Nakamura A, Kondo N, Sakamoto S, Endo S, et al. Positional cloning of the gene for Nijmegen breakage syndrome. Nat Genet. 1998; 19(2): 179-181.

5. Varon R, Vissinga C, Platzer M, Cerosaletti KM, Chrzanowska KH, Saar K, et al. Nibrin, a novel DNA double-strand break repair protein, is mutated in Nijmegen breakage syndrome. Cell. 1998; 93(3): 467-447. 
6. Saar K, Chrzanowska KH, Stumm M, Jung M, Nurnberg G, Wienker TF, et al. The gene for the ataxia-telangiectasia variant, Nijmegen breakage syndrome, maps to a $1 \mathrm{cM}$ interval on chromosome 8q21. Am J Hum Genet. 1997; 60(3): 605-610.

7. Cerosaletti KM, Lange E, Stringham HM, Weemaes CM, Smeets D, Sölder B, et al. Fine localization of the Nijmegen breakage syndrome gene to 8q21: Evidence for a common founder haplotype. Am J Hum Genet. 1998; 63(1): 125-134.

8. D'Amours D, Jackson SP. The Mre11 complex at the crossroads of DNA repair and checkpoint signaling. Nat Rev Mol Cell Biol. 2002; 3(5): 317-327.

9. Varon R, Seemanowa E, Chrzanowska K, Hnateyko O, Piekutowska-Abramczuk D, Krajewska-Walasek M, et al. Clinical ascertainment of Nijmegen breakage syndrome (NBS) and prevalence of the major mutation, 657del5, in three Slav populations. Eur J Hum Genet. 2008; 8(11): 900-902.

10. Chrzanowska K, Piekutowska-Abramczuk D, Popowska E, Gładkowska-Dura M, Małdyk J, Syczewska M, et al. Carrier frequency of muta- tion $657 \mathrm{del} 5$ in the NBS1 gene in a population of Polish pediatric patients with sporadic lymphoid malignancies. Int J Cancer. 2006; 116(5): 1269-1274.

11. di Masi A, Antoccia A. NBS1 Heterozygosity and cancer risk. Curr Genomics. 2008; 9(4): 275-281.

12. Reiter A, Schrappe M, Parwaresch R, Henze G, Müller-Weihrich S, Sauter S, et al. Non-Hodgkin's lymphoma of childhood and adolescence: Results of a treatment stratified for biologic subtypes and stage - A report of Berlin-Frankfurt-Münster Group. J Clin Oncol 1995; 13(2): 359-372.

13. Dembowska Baginska B, Perek D, Brozyna A, Wakulinska A, Olczak Kowalczyk D, Gladkowska Dura M, et al. Non Hodgkin lymphoma (NHL) in children with Nijmegen Breakage syndrome (NBS). Pediatr Blood Cancer. 2009; 52(2): 186-190.

14. Gregorek H, Chrzanovska KH, Michalkiewitz J, Syczewska M, Madalinski K. Heterogeneity of humoral immune abnormalities in children with Nijmegen breakage syndrome: An 8-year follow-up study in a single centre. Clin Exp Immunol. 2002; 130(2): 319-324. 